\title{
Memória empresarial: \\ uma proposta teórico-conceitual
}

Organizational memory:

a theoretical and conceptual proposal

Memoria empresarial:

una propuesta teórico-conceptual

Renata Cássia Andreoni de Souza

- Doutoranda em Comunicação Social na Pontifícia Universidade Católica do Rio Grande do Sul (PUC-RS)

- Mestre em Comunicação Social pela PUC-RS

- Especialista em Gestão Cultural, Patrimonial e Turismo Sustentável pela Fundación Ortega y Gasset (Foga), Buenos Aires

- Graduada em História pelo Centro Universitário Metodista do Sul (IPA)

- Idealizadora e ex-coordenadora da Unidade de Documentação e Memória da Cia. Carris Porto-Alegrense

- E-mail: andreoni.renata@gmail.com 


\section{Resumo}

Este artigo apresenta uma proposta teórico-conceitual sobre a memória empresarial, entendendo-a como fonte constituinte de discursos organizacionais. Esses discursos são percebidos como produtos e produtores de uma tríade conceitual, formada por memória, comunicação e poder. Nesta perspectiva, a memória empresarial se constitui a partir dessa tríade. Propomos perceber e dialogar a respeito das potencialidades afetivas da memória (pertencimento, vínculos, identidade), mas, também, suas competências mais pragmáticas (saberes e informações) que podem atuar sobre a gestão do conhecimento.

\section{PALAVRAS-CHAVE: MEMÓRIA • COMUNICAÇÃO•PODER・ORGANIZAÇÕES・MEMÓRIA EMPRESARIAL.}

\section{Abstract}

This article presents a theoretical and conceptual proposal on organizational memory, understanding it as being a constituent source of organizational discourses. Such discourses are perceived as products and producers of a conceptual triad consisting of memory, communication and power. In this perspective, organizational memory is created as from such triad. We propose to perceive and dialogue on the affective potentialities of memory (belonging, bonds, identity), but also their more pragmatic competencies (knowledge and information), which may impact on knowledge management.

\section{KEYWORDS: MEMORY・COMMUNICATION・POWER・ORGANIZATIONS・ORGANIZATIONAL MEMORY.}

\section{Resumen}

Este artículo presenta una propuesta teórico-conceptual sobre la memoria empresarial, entendiéndola como fuente constituyente de discursos organizacionales. Estos discursos son percibidos como productos y productores de una tríade conceptual, formada por memoria, comunicación y poder. En esta perspectiva, la memoria empresarial se constituye a partir de esa tríade. Proponemos percibir y dialogar al respecto de las potencialidades afectivas de la memoria (pertenencia, vínculos, identidad), sino, también, sus competencias más pragmáticas (saberes e informaciones), pudiendo actuar sobre la gestión del conocimiento. 
$\mathrm{N}$ esta reflexão, partimos da perspectiva que as áreas do conhecimento não se estruturam como compartimentos herméticos e díspares, mas proposições complementares que conjugam formações de desenvolvimento e percepções. De acordo com Edgar Morin (2013), podemos tentar suprir essa carência cognitiva combatendo as cegueiras de um modo de conhecimento que, compartimentando saberes, fragmenta as análises que demandam um conhecimento transdisciplinar.

Este artigo apresenta caminhos para compreender a memória empresarial' , a partir da complexidade ${ }^{2}$, associada à comunicação organizacional e às relações de poder. Nessa perspectiva, entendemos a memória institucional como fonte constituinte de discursos, produzidos por e produtores de uma tríade conceitual formada por memória, comunicação e poder. Neste trabalho, apresentamos uma proposta teórico-conceito sobre a memória empresarial, desenvolvida ao longo de uma pesquisa de mestrado ${ }^{3}$. Na reflexão, propomos a compreensão da memória empresarial a partir da imbricação desses conceitos (memória-comunicação-poder), elucidando seus impactos sobre a cultura organizacional, analisando suas possibilidades de intersecção e influência sobre a (re)constituição de vínculos e conhecimentos. Assim, propomos perceber e dialogar a propósito das potencialidades afetivas da memória sobre pertencimento e identidade, mas, também, suas competências mais pragmáticas, relacionadas à informação, aos saberes e conhecimentos da e na organização, podendo atuar sobre a gestão do conhecimento.

\section{TRACANDO O CENÁRIO E CAMINHOS}

Podemos observar que, nos últimos anos, há um pungente crescimento de projetos de memória em pequenas, médias e grandes empresas. Trata-se de uma tendência que vem crescendo no Brasil desde meados da década de 1990. Essas propostas são organizadas de diferentes maneiras, como formação de centros de documentação e memória, publicação de livros, organização de exposições, trabalhos de memória oral ${ }^{4}$, entre outras.

Paulo Nassar (2006) destaca que a responsabilidade histórica passa a fazer parte da responsabilidade social, à medida que há a compreensão dos gestores de seu papel histórico dentro de seu segmento e de sua comunidade. Tal prerrogativa se torna cada vez mais presente nas missões das instituições. Essas iniciativas alteram as relações da empresa com seus públicos, proporcionando um novo diálogo com a sociedade. Dessa forma, podemos identificar uma nova preocupação entre os gestores, pois compartilhar as histórias e memórias de uma empresa passa a ser também uma questão estratégica. Assim, "as operações com a história entraram no mercado simbólico do capitalismo tardio com tanta eficiência como quando foram objeto privilegiado das instituições escolares, desde o fim do século XIX" (Sarlo, 2007, p. 10). As organizações, quando sensíveis ao seu entorno e às relações que se (re)constituem ao longo de suas trajetórias, demonstram compreender que "são agentes sociais, participantes do desenvolvimento do país e que, por isso mesmo, devem retribuir com a memória que ajudaram a construir" (Nassar, 2006, p. 24). Para Sara Barbosa Sousa (2010, p. 78),

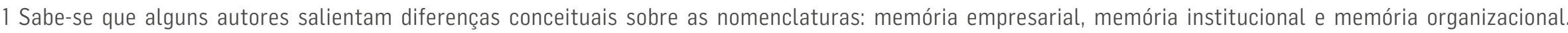
Entretanto, nesta abordagem, as utilizamos como sinônimos.

2 Nossa compreensão sobre complexidade, nesta reflexão, se sustenta no pensamento desenvolvido e apresentado por Edgar Morin (2003, 2005, 2007, 2008, 2013).

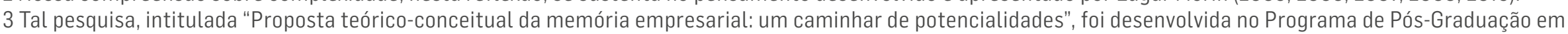

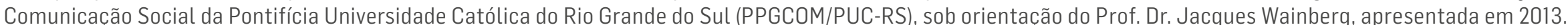

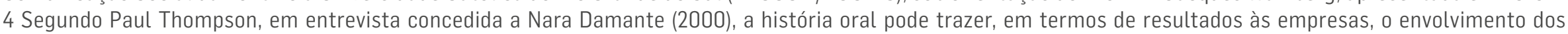

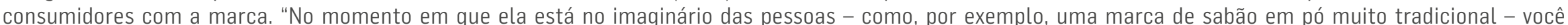

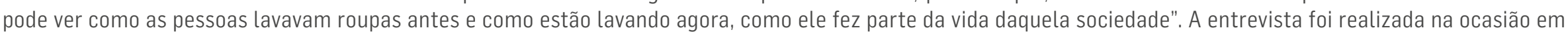

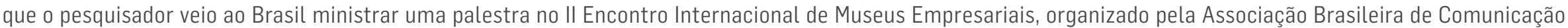
Empresarial (Aberje), em 2000 
a responsabilidade histórica empresarial tem por objetivo a valorização da memória das empresas e as relações entre a história, a área de atuação e o relacionamento da organização com seus diversos públicos (cliente, consumidor, colaborador e comunidade).

A historiadora Karen Worcman (2004), fundadora e diretora do Museu da Pessoa ${ }^{5}$, também ressalta a importância da memória na empresa como elemento de responsabilidade social e histórica. Entretanto, chama a atenção para o grande desafio de saber utilizar essa memória:

Trabalhar a memória empresarial não é simplesmente referir-se ao passado de uma empresa. Memória empresarial é, sobretudo, o uso que uma empresa faz da sua história. E dependerá da forma de perceber e valorizar sua própria história que as empresas podem aproveitar (ou perder) a oportunidade de utilizar essa ferramenta fundamental para adicionar mais valor à sua atividade (Worcman, 2004, p. 23).

0 cenário em que visualizamos esse entendimento e comprometimento das empresas, sobre suas memórias, caracterizase pelo efêmero, pela ansiedade, vulnerabilidade, busca de identidade e obsessão pelo tempo numa sociedade globalizada e tecnológica. Conforme Andreas Huyssen (2000), contemporaneamente a memória vem ganhando enfoque e destaque devido à ausência do sentimento de segurança, em uma sociedade profundamente caracterizada pela instabilidade do tempo e fragmentação do espaço.

As noções de tempo e espaço estão desestabilizadas pelas transformações tecnológicas; o presente não se concentra mais sobre a recordação e a esperança, na relação histórica entre o passado experimentado e o futuro como horizonte de expectativas (Koselleck, 2006). Assim, podemos perceber, no contexto atual, a expansão do espaço sincrônico, constituindo uma nova realidade espaçotemporal. De acordo com Huyssen (2000, p. 29), "quanto mais o capitalismo de consumo avançado prevalece sobre o passado e o futuro, sugando-os em um espaço sincrônico em expansão, menor a estabilidade ou a identidade que proporciona aos assuntos contemporâneos".

A onda mnêmica ${ }^{6}$ que permeia o presente pode ser encarada como um processo estratégico de controle sobre a condição efêmera das relações de identificações. Nesse cenário, podemos dizer que as relações com a memória estão elevadas à potência superlativa, na qual o antigo - o retrô - e o nostálgico se tornaram elementos que agregam valor. A busca de subsídios do passado se constitui como uma faceta para um consumo intimizado (Lipovetsky, 2004), no qual se compram e se vendem reminiscências, emoções, sensações e identificações. "Realmente, ao pensarmos nas coleções de carros antigos, de maços de cigarro, de vinhos, de vestuário, e outras mais, vemos que essas assumem o status de arte ou de objeto histórico, caracterizando o que passamos a chamar de ação museica" (Pinheiro, 2007, p. 174).

Dessa forma, destacamos a memória como uma prática para a estratégia organizacional, atuando sobre as relações de poder, de constituição de identidade e de conhecimento. Assim, a gestão da(s) memória(s) pode se manifestar como um importante processo para as organizações.

\section{PROPOSTA TEÓRICO-CONCEITUAL}

A preocupação centrada na acumulação de riquezas leva à "subordinação ao universo dos objetos-mercadorias e à racionalidade econômica" (Chanlat, 1993, p. 25). Nesse sentido, no interior das organizações, os indivíduos são reduzidos

5 Mais informações disponíveis em: <http://www.museudapessoa.net/_index.php/v2013/home>.

6 Referente à memória, a palavra mnêmica advém da Grécia Arcaica, época em que fizeram da memória uma deusa, Mnemosine, mãe de Clio - musa da História - e de mais oito musas procriadas ao longo das nove noites passadas com Zeus (Le Goff, 2003). 
a objetos/recursos/ferramentas que "devem" (grifo nosso) atender a rendimentos satisfatórios. Tal condição pode levar as pessoas a buscarem suas realizações fora do ambiente organizacional.

No entanto, as mudanças da contemporaneidade tendem a nos conduzir a um caminho mais longínquo e complexo na busca de compreender as novas formas de gestão e relação das organizações com os seus públicos. Entender a organização não como um sistema fechado, mas em constante relação de reciprocidade com o meio ambiente ${ }^{7}$.

Segundo Jean-François Chanlat (1993), o comportamento organizacional se estrutura como uma imensa colcha de retalhos, um campo aberto a quase todos os ventos teóricos. No interior desse conjunto heterogêneo, situam-se as seguintes dimensões: cognitiva e da linguagem; espaçotemporal; psíquica e afetiva; simbólica; da alteridade; e psicopatológica. Portanto, nessa perspectiva, buscamos perceber a organização compreendendo suas complexidades, rompendo com possíveis percepções reducionistas, que partem apenas do viés econômico e burocrático. De acordo com Morin (2008, p. 99),

pode dizer-se que o que é complexo revela por um lado do mundo empírico, da incerteza, da incapacidade de estar seguro de tudo, de formular uma lei, de conceber uma ordem absoluta. Revela por outro lado de algo lógico, quer dizer, da incapacidade de evitar contradições.

Nosso enfoque abarca as dimensões simbólicas, as representações afetivas, os elementos intangíveis, as relações de poder que se (re)estabelecem no ambiente organizacional a partir da gestão de suas memórias. Para tanto, esta análise parte da perspectiva da complexidade, proposta por Morin (2003; 2005; 2007; 2008; 2013), constituída por três etapas. Para elucidar sua análise, o autor estabelece uma relação da realidade social com uma tapeçaria contemporânea, composta por uma pluralidade de fios com espessuras, texturas e tonalidades distintas. Assim, a primeira etapa expõe que

\footnotetext{
a tapeçaria é mais do que a soma dos fios que a constituem. Um todo é mais do que a soma das partes que o constituem. Segunda etapa da complexidade: 0 fato de que existe uma tapeçaria faz com que as qualidades deste ou daquele não possam todas exprimir-se plenamente. Estão inibidas ou virtualizadas. 0 todo é então menor que a soma das partes. Terceira etapa: (...) 0 todo é simultaneamente mais e menos que a soma das partes (Morin, 2008, p. 123-124 - grifos do autor).
}

0 fato de analisarmos uma estrutura em sua pretensa totalidade não nos permite ignorar suas unidades e pluralidades. Da mesma forma, quando realizado um recorte focalizado, não se pode desconsiderar a multiplicidade no qual ele está inserido. Portanto, propomos considerar a unidade na diversidade, assim como a diversidade na unidade. Em oposição a pilares que orientaram a ciência clássica, como os princípios da redução e da separabilidade, que isolam os objetos de seus meios, temos a indissociabilidade, propondo uma via de aproximação, diálogo e relação, buscando pontos de confluência entre as complexas singularidades da matéria e do espírito. Para melhor compreendermos essa condição complexa, apresentamos três dos sete princípios $^{8}$, que constituem o paradigma moriniano da complexidade, a saber: o dialógico, o recursivo e o hologramático ${ }^{9}$.

7 Compreende-se "meio ambiente" como contexto no qual a organização está inserida, a realidade social que coabita suas estruturas

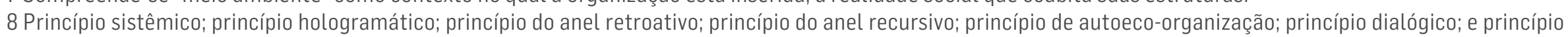
da reintrodução (Morin, 2008).

9 A escolha por esses três princípios se justifica pelo fato de que Morin (2008) os coloca como os três princípios basilares para se pensar a complexidade. 
Para além da significação de relação dialógica que pressupõe a justaposição da fala entre dois ou mais indivíduos, o princípio dialógico, para Morin, possibilita a percepção da presença de questões aparentemente contraditórias como complementares. Nesse caso, a dialógica é composta por lógicas distintas, associando termos complementários e antagônicos, permitindo a manutenção da "dualidade no seio da unidade" (Morin, 2008, p. 107). Esse princípio nos permite entender e perceber as estruturas e os fenômenos sem anular suas características, pois essas são fundamentais para suas constituições. Nosso olhar dialógico para a memória na organização pode ser elucidado na reflexão proposta por Morin (2005):

Há não somente justaposição e tolerância, mas também dialógica entre ordem e desordem cerebral, discurso lógico e vapores fantasmáticos; nessa dialógica, o imaginário pode transformar-se em imaginação e a ideia "louca" estimular ou enriquecer 0 pensamento racional (Morin, 2005, p. 112 - grifo do autor).

O princípio da recursividade vem romper com a linearidade e com o princípio de causalidade, propondo uma perspectiva de processo onde produtos e produtores interagem um sobre o outro. Em vez de uma análise baseada em causas e consequências, identificamos um contexto espiralado, no qual as produções e os produtos se constituem de maneira recíproca e simultânea.

\begin{abstract}
Nós, indivíduos, somos os produtos de um processo de reprodução que é anterior a nós. Mas, uma vez que somos produzidos, tornamo-nos os produtores do processo que vai continuar. (...) Os indivíduos produzem a sociedade que produz os indivíduos. Somos simultaneamente produzidos e produtores. A ideia recursiva é, portanto, uma ideia em ruptura com a ideia linear de causa/ efeito, de produto/produtor, de estrutura/superestrutura, uma vez que tudo o que é produzido volta sobre o que produziu num ciclo ele mesmo autoconstitutivo, auto-organizador e autoprodutor (Morin, 2008, p. 108).
\end{abstract}

Mais uma vez, com a proposta de romper com percepções reducionistas e separatistas, apresentamos o terceiro princípio, o hologramático. "É um pouco a ideia formulada por Pascal: 'Não posso conceber o todo sem conceber as partes e não posso conceber as partes sem conceber o todo'" (Morin, 2008, p. 109 - grifo do autor). Isso implica dizer que o todo não é simplesmente a soma das partes, nem apenas reduzir a parte como constituinte do todo. Portanto, nesta perspectiva, "não apenas a parte está no todo mas o todo está na parte" (Morin, 2007, p. 67).

É a partir da (inter)ligação entre esses três princípios que direcionamos nosso olhar para as perspectivas e potencialidades dos projetos/programas de memória empresarial, entendendo a empresa como um organismo vivo, situada em um ambiente exterior que interage sobre ela, assim como ela interage sobre ele, constituindo um ecossistema. Dessa forma, a empresa é contextualizada sobre um sistema autoeco-organizado (Morin, 2005).

Assim, para seguirmos o caminho, valemo-nos de pressupostos fundamentais para a construção desta trajetória. Por meio das lentes constituídas pelo paradigma da complexidade, a partir dos três princípios apresentados, esboçamos, através do diagrama da Figura 1, uma proposta teórico-conceitual sobre as (inter)relações e imbricações que entendemos pertinentes para (re)pensar, compreender e desenvolver um projeto/programa de memória organizacional. A opção por apresentar nosso pensamento por meio de uma ilustração se dá pelo fato de entendermos que esta é uma forma para melhor explicitarmos a construção desta reflexão. 
Figura 1 - Diagrama da proposta teórico conceitual

PROJETO/PROGRAMA DEMEMÓRIA

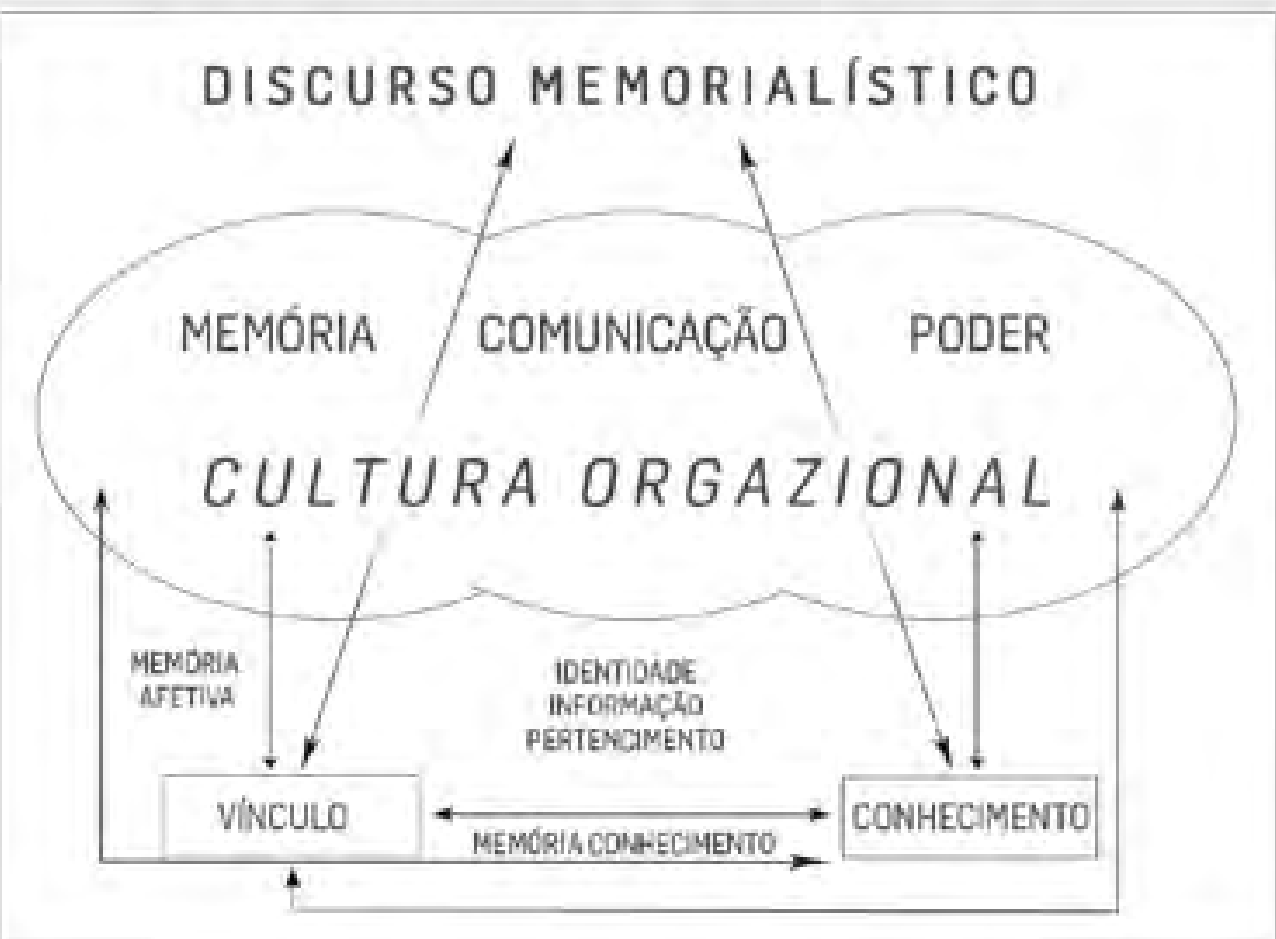

Fonte: Elaborada pela autora a partir do paradigma da complexidade, através dos princípios dialógico, recursivo e hologramático.

As ações e os processos desenvolvidos através de projetos/programas de memória empresarial são percebidos aqui como discursos construídos, produzidos por e produtores de memória, comunicação e poder. Na imbricação desses três conceitos, temos a cultura organizacional, impactada e impactando a (re)constituição de vínculos e conhecimentos. Nesse sistema denominado complexus ${ }^{10}$, podemos mapear perspectivas mais afetivas da memória sobre pertencimento e identidade, assim como, também, suas competências mais pragmáticas, relacionadas à informação, aos saberes e aos conhecimentos da e na organização. Nessa proposta, as interações vão se estabelecendo sem seguir um fluxo específico, mas transpondo as barreiras da unidirecionalidade, interagindo de forma horizontal e vertical; por conseguinte, todos os elementos do diagrama acabam se relacionando, através de diferentes convergências.

Nossa abordagem propõe o discurso memorialístico como produto e produtor de seus elementos formadores. É por meio dessa relação recursiva que ele se (re)estrutura. 0 discurso memorialístico representa a nossa totalidade, composta pelas partes que possibilitam a sua formação. Entretanto, isso só é possível porque ele está presente em cada uma delas; portanto, percebemos o discurso a partir de uma alusão à figura de um holograma. Por exemplo, o discurso constrói 0 conhecimento, mas também é construído por ele; da mesma forma que o discurso está no conhecimento, o conhecimento está no discurso. "Então pode enriquecer-se o conhecimento das partes pelo todo e do todo pelas partes, num mesmo movimento produtor de conhecimentos" (Morin, 2008, p. 109). Assim, estabelecem-se as relações com os demais elementos que estão presentes no diagrama.

Por fim, partimos do pressuposto de que as construções de discursos memorialísticos passam por um processo de seleção. Nesse caso, a dialógica se estabelece entre a polifonia de vozes que vivenciam, direta e indiretamente, a história da organização. Ao direcionarmos o olhar sobre o diagrama, percebe-se a profunda (inter)relação entre cada parte que compõe 


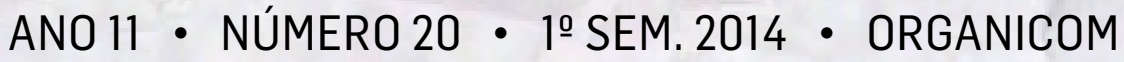 \\ MEMÓRIA EMPRESARIAL: \\ UMA PROPOSTA TEÓRICO-CONCEITUAL}

essa estrutura sistêmica-hologramática. Para a formação dos discursos memorialísticos, identificamos a associação de termos antagônicos, porém complementares: a lembrança e o esquecimento; os bem-ditos, não-ditos e mal-ditos " ; 0 válido e o inválido. É a partir dessa relação dialógica que se estruturam a memória, a comunicação e o poder. Nessa perspectiva, os discursos memorialísticos são constituídos através deles; incidem sobre eles e constituem novas memórias, comunicações e relações de poder, permitindo a criação de novos discursos. Assim, percebemos os projetos/programas de memória como (re)produtores e gestores de discursos organizacionais.

0 discurso memorialístico não é homogêneo, já que é formado por uma multiplicidade de elementos, pluralidade de vozes e relações de forças que vão se (re)estabelecendo e se (re)estruturando a partir de processos seletivos. Portanto, o discurso memorialístico é composto por informações, saberes, conhecimentos, afetividades e sensibilidades que despertam e (re) constroem sentidos e significados, através das relações de poder, da memória e da comunicação organizacional ${ }^{12}$. Tal processo se estabelece quando a articulação e a (inter)relação dos conceitos que apresentamos como partes constitutivas do discurso memorialístico, gestionados através da memória, constituem o que chamamos de memórias afetivas (MA) e memórias-conhecimento (MC). A gestão da MA e da MC, nos diferentes processos da organização, realizada de forma integrada, transversal e contínua, estabelece-se a partir de processos que denominamos gestão da memória afetiva (GMA) e gestão da memória-conhecimento (GMC). Com o objetivo de esclarecer esse pensamento sobre a representatividade da GMA e da GMC em nossa proposta de projeto/programa de memória empresarial, apresentamos o diagrama da Figura 2.

Figura 2 - Diagrama GMA e GMC.

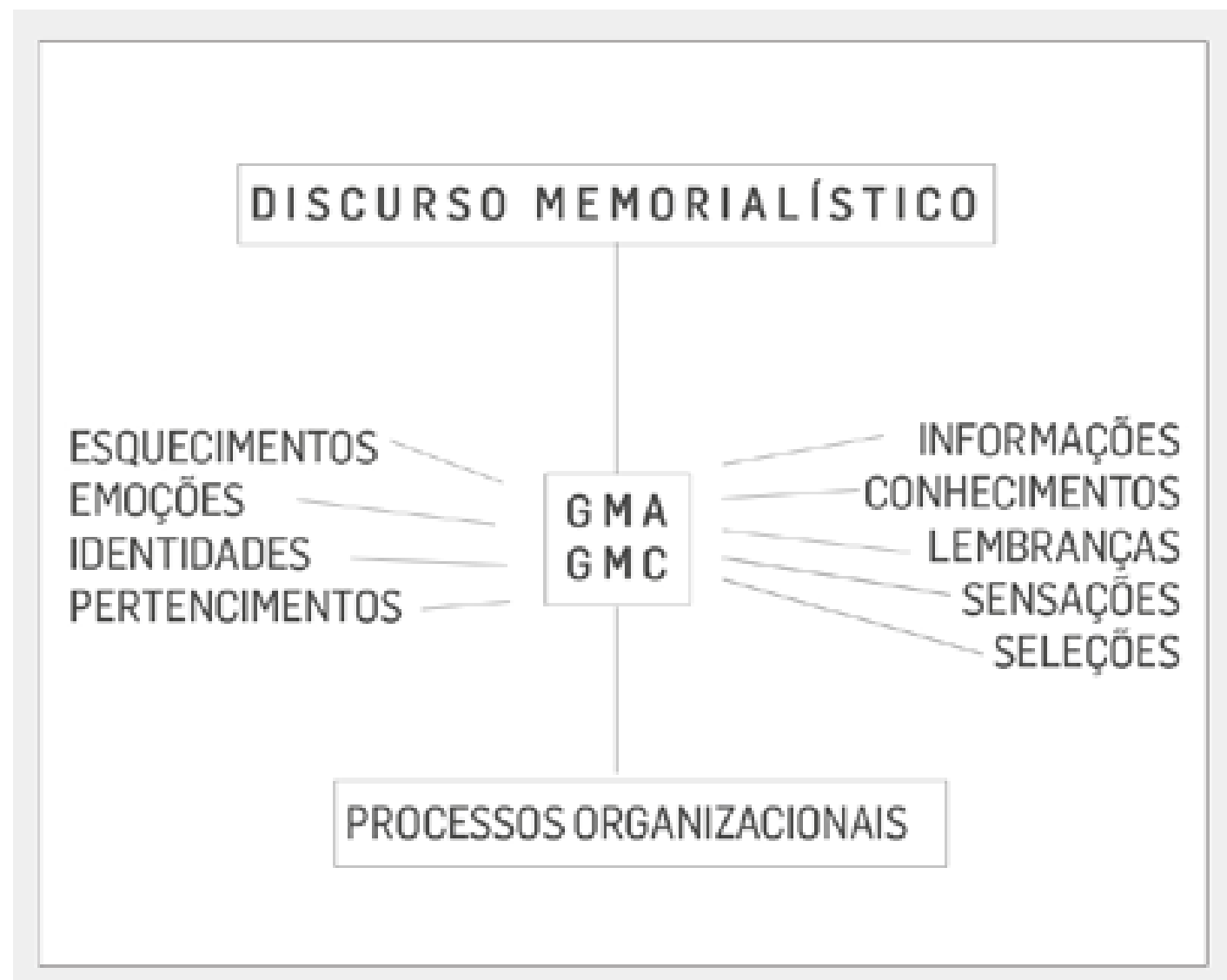

Fonte: Elaborada pela autora para elucidar a relação dos discursos memorialísticos com os demais processos da empresa, a partir da GMA e GMC.

11 De acordo com Roman (2009), as organizações contemporâneas se constituem em universos de discursos bem-ditos, mal-ditos e não-ditos. "Bem-ditos são os enunciados institucionais, formais ou informais. Mal-ditos, por sua vez, são os enunciados clandestinos, boatos rumores e as 'fofocas' que circulam na 'rádio-corredor' e em outros espaços liminares. Bem-ditos e mal-ditos são antagônicos e complementares. (...) A interdição do mal-dito gera discursos não-ditos" (Roman, 2009, p.125). 12 "Entende-se que a comunicação organizacional abrange todas as formas/modalidades de comunicação utilizadas e desenvolvidas pela organização para relacionar-se e interagir com seus públicos (Scroferneker, 2006, p. 48). 
As memórias, as afetividades e os conhecimentos presentes na organização não representam por si só GMA e/ou GMC. Na proposta que apresentamos, a MA e a MC se (re)constituem quando as afetividades e os conhecimentos dispersos são administrados através dos projetos/programas de memória empresarial. Entretanto, a GMA e a GMC só se configuram à medida que a organização trabalha sobre a gestão de suas afetividades e de seus conhecimentos, por meio de suas memórias, de forma permanente e integrada às demais áreas da empresa. A GMA e a GMC são formas de as organizações desenvolverem a gestão de suas memórias de maneira indissociável dos demais processos da empresa. Nesse sentido, a partir do pensamento complexo, propomos trabalhar a memória empresarial da e na organização de forma transversal.

A ideia hologramática está ligada à ideia recursiva, que por sua vez está em parte ligada à ideia dialógica. (...) Os princípios do pensamento complexo serão necessariamente princípios de distinção, de conjunção e de implicação. Juntai a causa e o efeito, e 0 efeito voltará sobre a causa, por retroacção, o produto será também produtor (Morin, 2008, p. 109-112).

A elaboração dessa proposta teórico-conceitual a partir do paradigma da complexidade, ancorado em seus princípios fundantes (dialógico, recursivo e hologramático), é uma possibilidade que apresentamos para (re)pensar, perceber, compreender e desenvolver projetos/programas de memória empresarial. Tal proposta foi elaborada a partir de uma reflexão desenvolvida sobre a tríade memória, comunicação e poder, traçando possíveis caminhos conceituais que nos permitiram desenvolver esta perspectiva. Essa proposta se apresenta no sentido de traçar um caminho teórico para elucidar como a percepção, a compreensão e o desenvolvimento dos projetos/programas de memória empresarial - trabalhados de forma contínua e transversal - podem influenciar e se relacionar aos demais processos da gestão organizacional.

\section{CONSIDERAÇÕES FINAIS}

Ações mnêmicas esparsas e produtos de memória comemorativos podem acabar por estigmatizar a memória empresarial como sinônimo de atividades e produções celebrativas, com potencialidades efêmeras. Nessa abordagem, a memória tende a ser percebida e desenvolvida como algo "menor" (grifo nosso) na instituição, com esforços e efeitos sazonais. Sob outra perspectiva, apresentamos nosso olhar a partir da elaboração de uma proposta teórico-conceitual para (re)pensarmos, compreendermos e desenvolvermos a memória nas organizações. Para tanto, buscamos no paradigma da complexidade a transversalidade que a memória empresarial nos possibilita.

Pensar sobre uma prática que está em processo de constituição, incipiente no contexto organizacional, demanda reflexão e proposição. Nesse sentido, identificamos a necessidade de trabalhar a teorização da memória empresarial, corroborando o desenvolvimento de um senso crítico sobre a temática. Para tanto, apresentamos uma proposta teórico-conceitual, para que a elaboração e a execução de projetos/programas de memória empresarial possam partir de referências teóricas, embasando as práticas e as potencialidades da memória nos ambientes organizacionais/institucionais.

Trabalhar a memória organizacional de maneira comemorativa e sazonal faz parte do senso comum. As empresas, ao se aproximarem da data de sua fundação, são conduzidas a pensarem na importância da sua história e de suas memórias, impulsionando o desenvolvimento de ações e produtos memorialísticos/comemorativos. Esse "despertar" (grifo nosso) é intensificado nos momentos em que se comemoram as viradas de décadas, por representarem o cumprimento de mais um ciclo de atuação e produção. Dessa forma, podemos perceber a memória empresarial baseada em premissas constituídas pelo senso comum. 
As especificidades da contemporaneidade nos incitam a buscar novas respostas, a refletir sobre as estruturas através de outras perspectivas. Pensar sobre as organizações de forma complexa, para além das justaposições maniqueístas, permitiunos constituir um olhar sobre a memória empresarial associado às relações de poder e à comunicação organizacional. Nesse sentido, acreditamos que esta proposta contribui com os estudos e com as práticas memorialísticas nas organizações.

Entendemos que a perspectiva que apresentamos para se (re)pensar, compreender e desenvolver a memória organizacional é pertinente na sociedade contemporânea. Sob um cenário de instabilidade, descontinuidade, insegurança, fragmentação, acúmulo de informações e vulnerabilidade, faz-se importante administrar recursos humanos nos espaços sociais e organizacionais. Nessa perspectiva, os projetos/programas de memória se constituem como ativos intangíveis nos processos da gestão organizacional. Por conseguinte, o trabalho de memória empresarial representa uma possibilidade de administrar a pluralidade de sentidos e significações, despertados e (re)constituídos através de memórias afetivas (MA) e memórias-conhecimento (MC).

Esperamos que este trabalho seja provocador, no sentido de nos incentivar a aprimorar um senso crítico sobre a memória empresarial, ancorando nossas percepções e ações sobre pressupostos teóricos. A proposta que apresentamos pode ser utilizada como uma matriz estruturante/conceitual para análises de ações/produtos desenvolvidos por projetos/programas de memória empresarial. A matriz possibilita a investigação (análise) sobre os discursos memorialísticos organizacionais, buscando identificar a evocação e (re)constituição de sentidos e significados, através do mapeamento de potencialidades afetivas (MA) e pragmáticas (MC) da memória empresarial, buscando, também, identificar a gestão dessas memórias na estratégia e nos processos organizacionais, através da GMA e da GMC.

\section{REFERÊNCIAS}

CHANLAT, Jean-François. Por uma antropologia da condição humana nas organizações. In: TORRES, Ofélia L. S. O indivíduo na organização: dimensões esquecidas. São Paulo: Editora Atlas, 1993. p. 21-45.

DAMANTE, Nara. Recordar é viver. [s. d.]. Entrevista com Paul Thompson. Disponível em: <http://www.aberje.com.br/revista/ antigas/rev_36_entrevista.htm> Acesso em: 05 ago. 2010.

HUYSSEN, Andreas. Seduzidos pela memória: arquitetura, monumentos, mídia. 2. ed. Rio de Janeiro: Aeroplano, 2000.

KOSELLECK, Reinhart. Futuro passado. Rio de Janeiro: Contraponto / Ed. PUC-Rio, 2006.

LE GOFF, Jacques. História e memória. Campinas, Editora Unicamp, 2003.

LIPOVETSKY, Gilles. Tempos hipermodernos. São Paulo: Barcarolla, 2004.

MORIN, Edgar. A via para o futuro da humanidade. Rio de Janeiro: Bertrand Brasil, 2013. . Introdução ao pensamento complexo. 5. ed. Lisboa: Instituto Piaget, 2008. 
Educação e complexidade: os sete saberes e outros ensaios. 4. ed. São Paulo: Cortez, 2007.

0 método - 3. 0 conhecimento do conhecimento. 3 ed. Porto Alegre: Sulina, 2005.

0 método - 5. A humanidade da humanidade: a identidade humana. Porto Alegre: Sulina, 2003.

ROMAN, Artur Roberto. Organizações: um universo de discursos bem-ditos, mal-ditos e não-ditos. In: KUNSCH, Margarida M. Krohling. Comunicação organizacional. Vol. 2. Linguagem, gestão e perspectivas. São Paulo: Saraiva, 2009. p. 125-157.

SARLO, Beatriz. Tempo passado. São Paulo: Companhia das Letras, 2007.

SCROFERNEKER, Cleusa Maria Andrade. Trajetórias teórico-conceituais da comunicação organizacional. Famecos - Mídia, Cultura e Tecnologia, Porto Alegre, PUC-RS, n. 31, dez. 2006.

SOUSA, Sara Barbosa. Memória empresarial: interesse utilitarista ou responsabilidade histórica. São Paulo: Dissertação (Mestrado em Ciências da Comuicação) - Escola de Comunicações e Artes da Universidade de São Paulo (ECA-USP), 2010.

WORCMAN, Karen. Memória do futuro: um desafio. In: NASSAR, Paulo (Org.). Memória de empresa: história e comunicação de mãos dadas, a construir o futuro das organizações. São Paulo: Aberje Editorial, 2004. p. 23-30.

Artigo recebido em 13.06.2014 e aprovado em 16.06.2014. 